\title{
Execução de Projetos de REDD+ no Brasil Por Meio de Diferentes Modalidades de Financiamento ${ }^{1}$
}

\author{
Guilherme Piffer Salles², Delhi Teresa Paiva Salinas ${ }^{3}$ e \\ Sônia Regina Paulino ${ }^{4}$
}

Resumo: No âmbito dos acordos globais sobre mudanças climáticas, o mecanismo para Redução de Emissões por Desmatamento e Degradação Florestal (REDD+) tem sido colocado como central para o incentivo econômico às medidas de mitigação envolvendo os ecossistemas florestais. O presente trabalho objetiva analisar as diferenças e as semelhanças dos projetos de REDD+ no Brasil sob distintas modalidades de financiamento, baseadas em fundos públicos ou no mercado de carbono. Utilizando testes de hipótese, dados são analisados, coletados em bases de dados de acesso público, para 18 variáveis de 89 projetos piloto, aprovados sob o mercado voluntário de carbono e sob o Fundo Amazônia. Verifica-se que os projetos sob cada modalidade de financiamento têm várias diferenças entre si, como as relativas a participantes, prazos, abrangência e práticas de Monitoramento, Relato e Verificação. Por outro lado, como aspecto semelhante, recorrem tanto aos pagamentos em dinheiro quanto aos incentivos não monetários, como fortalecimento institucional e provimento de infraestrutura. Isso explicita os esforços destes projetos em adaptar-se às complexidades do contexto florestal e à eficiência necessária para garantir resultados esperados do REDD+. Argumenta-se, assim, em favor da adoção de modalidades mistas de financiamento, capazes de incentivar simultaneamente projetos sob fundos públicos e sob mercados de carbono.

Palavras-chaves: REDD+, modalidades de financiamento, instrumentos econômicos, pagamentos por serviços ambientais.

Abstract: Under the global climate change agreements, the mechanism for Reducing Emissions from
Deforestation and Forest Degradation (REDD+) is paramount for the economic incentive of forest-
based mitigation measures. In order to analyse the similarities and differences between REDD+
projects in Brazil that are using public funds or carbon markets as its financing mechanism, this
study gathers project data from public access databases and applies statistical descriptive analysis

1. Data de submissão: 29 de fevereiro de 2016. Data de aceite: 18 de maio de 2017.

2. Universidade de São Paulo. São Paulo - SP, Brasil. E-mail: guilherme.piffer@alumni.usp.br

3. Universidade de São Paulo. São Paulo - SP, Brasil. E-mail: delhi@usp.br

4. Universidade de São Paulo. São Paulo-SP, Brasil. E-mail: sonia.paulino@usp.br 
and hypothesis testing to 18 variables that describe core project characteristics. Based on the analysis results for 89 pilot projects approved under the voluntary carbon market and the Amazon Fund, it is possible to identify that the projects under each category presents clear distinctions in characteristics related to participants, time periods, scope and monitoring reporting and verification. On the other hand, projects under both categories resort to both cash payments and non-monetary incentives such as institutional strengthening and infrastructure provision. The results pictures projects' efforts to adapt to the complexities of the forest sector and to the efficiency requirements necessary to achieve the expected REDD+ results. It is argued that a mixed financial mechanism should be adopted, in order to enable financing projects both under public funds and under carbon markets.

Key-words: REDD+ finance, economic instruments, payments for environmental services.

Classificação JEL: Q15, Q23, Q57, Q58.

DOI: http://dx.doi.org/10.1590/1234-56781806-94790550302

\section{Introdução}

Os ecossistemas florestais possuem papel central no combate às mudanças climáticas, já que a perda de florestas, junto a outros usos do solo não relacionados à agricultura, responderam por aproximadamente um terço das emissões de dióxido de carbono no período de 1750 a 2011 (IPCC, 2014). Além disso, são considerados ecossistemas vitais para a manutenção do sistema terrestre em uma situação de equilíbrio capaz de prover as condições para o desenvolvimento humano (ROCKSTRÖM et al., 2009; STEFFEN et al., 2015).

Por outro lado, trata-se de ecossistemas fortemente pressionados e que sofrem um efeito sistêmico negativo duplo: as florestas são inicialmente impactadas pelas mudanças no uso do solo, o que contribui para as mudanças climáticas, as quais, por sua vez, têm potencial para novamente impactar as florestas (MILLENNIUM ECOSYSTEM ASSESSMENT, 2005; NORGAARD, 2010). Assim, a adoção de medidas para a proteção das florestas, e a consequente redução das emissões e aumento de estoques de carbono florestais, são essenciais como parte do rol de medidas de mitigação das alterações climáticas globais.

Neste contexto, ganha importância o processo de criação de um mecanismo que incentive atividades de Redução de Emissões por Desmatamento e Degradação, incluindo conservação, manejo sustentável e aumento dos estoques de carbono florestal (REDD+) nos países em desenvolvimento, o qual vem sendo estruturado no âmbito da Convenção
Quadro das Nações Unidas sobre Mudança do Clima (UNFCCC).

Por sua vez, o Brasil possui extensa cobertura florestal e taxas de desmatamento que, apesar de historicamente altas, foram reduzidas nos últimos anos graças à aplicação de um conjunto de iniciativas de proteção às florestas (ARIMA et al., 2014). Dentre estas iniciativas estão políticas de comando e controle adotadas pelo governo e que promoveram maiores restrições ao desmatamento ilegal, tais como o fortalecimento de órgãos governamentais de gestão e fiscalização ambiental (ARRAES, MARIANO e SIMONASSI, 2012), a criação de áreas protegidas, a promoção de ordenamento territorial e as restrições ao crédito para municípios com altas taxas de desmatamento (LAPOLA et al., 2013), além do embargo à comercialização de produtos oriundos de áreas desmatadas ilegalmente (FERREIRA e COELHO, 2015).

Contudo, a volta do crescimento das taxas de desmatamento na Amazônia nos anos de 2015 e 2016, que registraram respectivamente aumentos de $24 \%$ e de 29\% (INPE, 2016), indica que estes avanços ainda não estão totalmente consolidados. Assim, os incentivos econômicos e os arranjos institucionais decorrentes da implantação do REDD+ podem complementar de forma substancial a estrutura político-institucional de proteção às florestas que vem sendo desenvolvida no Brasil, de forma a garantir as conquistas já obtidas e avançar ainda mais na redução das taxas de desmatamento (LAPOLA et al., 2013; SOARES-FILHO et al., 2014). 
O REDD+ deverá entrar integralmente em vigor como parte do Acordo de Paris (AP), que foi adotado em dezembro de 2015 durante a 21ํㅡㄹ Conferência das Partes da UNFCCC (COP 21) em Paris, e entrou em vigor em novembro de 2016 durante a COP $22 \mathrm{em}$ Marraquexe. O AP irá suceder o Protocolo de Quioto a partir de 2020, sendo que o REDD+ é citado em seu Artigo 5, o qual expressa que as partes signatárias devem atuar para conservar e ampliar os sumidouros e reservatórios naturais de gases de efeito estufa, incluindo as florestas (UNFCCC, 2016, 2017).

Em última instância é possível diferenciar entre as "Atividades de REDD+" em si e os mecanismos de incentivo usados para fomentá-las. Contudo, devido ao substancial custo envolvido, pode-se considerar que o mecanismo de incentivo econômico será central no levantamento dos recursos necessários para que os países implantem estas atividades (FOSCI, 2013b; VIANA, 2009). Tendo em conta esta centralidade, exceto quando explicitamente mencionado, o termo REDD+ será usado neste trabalho para referir-se de forma abrangente a este mecanismo de incentivo para adoção das Atividades de REDD+.

Em âmbito internacional, o REDD+ é construído tendo como referência instrumentos econômicos de política ambiental, já que envolve utilização de incentivos econômicos e não de regulação direta para alcançar seus objetivos ambientais. Considerando que o mecanismo estabelece que países em desenvolvimento detentores de florestas recebam recursos financeiros de países desenvolvidos para reduzir suas emissões atreladas ao setor florestal (UNFCCC, 2011, 2012), dentre os instrumentos econômicos, o REDD+ envolve notadamente o conceito de Pagamento por Serviços Ambientais (BÖRNER et al., 2010; CORBERA, 2012; HALL, 2013; LEDERER, 2011; MAHANTY, SUICH e TACCONI, 2013).

Assim, o financiamento das ações de REDD+ tem sido foco de um amplo debate ao longo das negociações (STRECK, 2012), e pode ocorrer por meio de diferentes modalidades. Por exemplo, pode tanto ser feito com a comercialização de reduções (créditos) de carbono florestal entre atores privados em um mercado de carbono quanto com o estabelecimento de fundos públicos de financiamento (VIANA, 2009). Estes fundos seriam utilizados pelos países em desenvolvimento para centralizar os recursos dos países desenvolvidos e distribuí-los internamente dentre os atores envolvidos nestas ações.
Aqui pode ser identificada uma das divergências de interpretação entre as correntes da economia ambiental neoclássica e da economia ecológica em relação aos objetivos e às estruturas que devem ser adotadas na concepção e execução de instrumentos econômicos de política ambiental. Na visão neoclássica, os sistemas de Pagamento por Serviços Ambientais (PSA) devem ser implantados a partir de transações de mercado entre provedores e beneficiários dos serviços ambientais (ENGEL, PAGIOLA e WUNDER, 2008). Já na visão da economia ecológica, o PSA deve ser implantado por meio de um conjunto de instrumentos de incentivo, com maior participação do Estado e podendo ou não envolver transações de mercado (MURADIAN et al., 2010, 2013; SANTOS e VIVAN, 2012).

Cabe destacar que, até o momento, as decisões 9/CP.19 (UNFCCC, 2013) e 1/CP.21 (UNFCCC, 2016) reforçam o papel do Green Climate Fund (GCF), um fundo estabelecido pela UNFCCC como o operacionalizador inicial do financiamento às ações de REDD+ no âmbito da convenção. Já o artigo 6 do AP estabelece as bases para um futuro mecanismo de mercado para incentivo às iniciativas de mitigação, mas não menciona e nem define regras específicas em relação ao REDD+ (UNFCCC, 2016).

Desta forma, tanto o AP, em seus artigos 5 e 6, quanto a COP 21, em sua decisão 1/CP.21 (parágrafo 54), mantêm em aberto as possibilidades em relação ao exato funcionamento dos mecanismos financeiros do REDD+, ficando, assim, pendentes definições mais específicas sobre as modalidades de financiamento que serão utilizadas no âmbito da UNFCCC para transferir os recursos para as iniciativas de mitigação florestal.

Entretanto, já na COP 16 foi estabelecido que o REDD+ deve ser implementado por fases, incluindo a elaboração de ações de preparação e projetos piloto de REDD+ pelos países em desenvolvimento, e legitimando processos paralelos de negociação bilateral e multilateral para a obtenção de fundos para estas ações, antes mesmo do fim das negociações sobre o mecanismo na UNFCCC (AGRAWAL, NEPSTAD e CHHATRE, 2011; STRECK, 2012).

Com isto, mesmo antes da entrada em vigor do novo acordo global, há no Brasil uma ampla gama de projetos de REDD+ utilizando distintas modalidades de financiamento, quais sejam: mercado, representado pelo Mercado Voluntário de Carbono (MVC), que vem se desenvolvendo de forma inde- 
pendente das negociações da UNFCCC (GOLDSTEIN e GONZALEZ, 2014); e fundo público, representado pelo Fundo Amazônia (FA), iniciativa do governo brasileiro para financiamento de atividades de REDD+ (BNDES, 2014; VIANA, 2009).

Justifica-se, assim, ampliar o conhecimento sobre as modalidades de financiamento de REDD + e seus possíveis impactos na implantação do mecanismo, temas que estão no cerne de um intenso debate, teórico e político, em curso sobre quais estruturas são mais indicadas para conferir eficácia e eficiência ao mecanismo. O objetivo do artigo é analisar as diferenças e as semelhanças no desenho e na forma de implantação dos projetos de REDD+ no Brasil sob cada modalidade de financiamento, via fundos públicos ou mercado. Com isso, pretende-se contribuir com o debate envolvendo as ações de REDD+ empreendidas no Brasil, o financiamento público e privado destas ações, e também as futuras posições do governo brasileiro nas negociações internacionais sobre a implantação do mecanismo.

O trabalho está organizado em cinco seções. Após essa introdução, a seção 2 localiza o REDD + no âmbito das concepções teórico-conceituais sobre instrumentos econômicos baseados em incentivo. A seção 3 apresenta os procedimentos metodológicos adotados no estudo e a seção 4 apresenta os resultados da pesquisa, discutindo as características dos projetos de REDD+ sob cada modalidade de financiamento. Por fim, as conclusões são apresentadas na seção 5 .

\section{REDD+ no âmbito dos instrumentos econômicos baseados em incentivo}

Os instrumentos econômicos vêm sendo considerados complementares ao comando e controle (COMMON e STAGL, 2005), mas há diferentes entendimentos teóricos sobre a conceituação e aplicação prática destes instrumentos. De acordo com a visão da economia ambiental neoclássica, o uso destes instrumentos está atrelado às características de bens públicos de muitos dos recursos naturais e dos benefícios por eles oferecidos. Estas características resultam em externalidades ${ }^{5}$, isto é, falhas de mercado que impedem a

5. Externalidades ocorrem quando um impacto positivo ou negativo é gerado por determinada atividade sem que o correta formação de preços, os quais são fundamentais para que o meio ambiente seja adequadamente considerado na dinâmica de mercado. Essa situação acaba por gerar incentivos para o excessivo uso dos recursos e a poluição dos ecossistemas (COMMON e STAGL, 2005; MOTTA, 2006, 2011).

Assim, estes instrumentos buscam atuar por meio do sistema de preços, tornando as atividades ambientalmente nocivas mais custosas para os atores envolvidos, sejam eles produtores ou consumidores. Com isso, buscam a internalização das externalidades, isto é, corrigir as falhas de mercado que originam o sobreuso dos recursos naturais e a suboferta de benefícios ambientais (JACOBS, 1997; LUSTOSA, CÁNEPA e YOUNG, 2003; MOTTA, 2011). Dentre as qualidades aventadas para a adoção deste tipo de instrumento, está sua maior flexibilidade e seu potencial para melhorar a alocação dos recursos, gerando soluções mais custo efetivas para o atingimento dos objetivos da política ambiental (CÁNEPA, 2003; MOTTA, 2006).

Um ponto interessante desta visão é que ela trata de forma subsidiária a questão da alocação inicial dos direitos, isto é, da distribuição, pelo Estado a atores privados, de direitos ao uso de recursos que antes tinham características de bens públicos. Por exemplo, o direito do produtor ao uso ou à degradação de recursos naturais para viabilizar sua produção; ou o direito da população à conservação destes recursos para a obtenção de uma melhor qualidade de vida. De acordo com Coase (1960), um dos expoentes desta visão, independentemente da distribuição inicial de direitos de propriedade, se os mesmos estiverem claramente definidos as partes podem negociar, e assim alcançar a alocação eficiente dos recursos. ${ }^{6}$

Contudo, mesmo que a alocação seja eficiente, esta distribuição inicial gera também resultados finais diferentes para as partes (ANDRADE; SIMÕES, 2013;

causador seja remunerado ou cobrado por este impacto. No caso dos ativos ambientais, o provedor do serviço ambiental não é remunerado pelos benefícios gerados por estes serviços (LANDELL-MILLS e PORRAS, 2002).

6. Coase relacionou externalidades à falta de direitos de propriedades bem definidos. Caso estes direitos possam ser definidos e não haja custos de transação para a negociação entre as partes, os atores poderiam negociar entre si de forma custo-efetiva as compensações pelos efeitos negativos, internalizando assim custos sociais que antes eram externalidades (GUEDES e SEEHUSEN, 2011; MOTTA, 2011). Este entendimento tem sido referenciado atualmente como Teorema de Coase ou visão coaseana. 
CÁNEPA, 2003). A aplicação desta visão traz constantemente consigo a discussão sobre a definição dos critérios a serem adotados pelo Estado para esta distribuição inicial de direitos. Alguns exemplos de critérios que podem ser citados incluem a justiça distributiva, que se preocupa com uma distribuição balanceada de ônus e de benefícios ambientais entre os diversos atores econômicos e sociais (FIGUEROA e MILLS, 2003); a manutenção de privilégios anteriores, com base em níveis históricos de uso dos recursos (DALY e FARLEY, 2004); e a responsabilidade comum, porém diferenciada, usado atualmente na UNFCCC como forma de considerar que todas as partes têm responsabilidades pela redução de emissões, mas estas responsabilidades serão maiores ou menores dependendo do nível histórico de contribuição de cada país para o problema (UNFCCC, 1998).

Outra perspectiva em relação ao uso dos instrumentos econômicos é apresentada pela economia ecológica, que argumenta ser necessário considerar, em primeiro lugar, a escala, isto é, os limites biofísicos dos ecossistemas envolvidos. Em seguida deve ser considerada a questão distributiva, para definir de forma justa a alocação de propriedade e de direitos de uso dos recursos naturais. Só então, deve-se considerar a questão da eficiência, buscando aproximar-se de uma alocação ótima do uso dos recursos para as diversas atividades econômicas, dadas a escala e a distribuição definidas anteriormente. (DALY e FARLEY, 2004; GÓMEZ-BAGGETHUN et al., 2010; SIMÃO, MARTINS e FAVARETO, 2014).

Assim, o mercado é entendido como uma ferramenta que pode ser utilizada para se atingir a alocação eficiente de recursos, mas não para a definição dos níveis desejados de atividade econômica (escala sustentável) ou a distribuição equitativa. Isto porque, mesmo sendo o mercado capaz de promover a alocação ótima de recursos para quaisquer configurações de direitos de propriedade, os resultados destes arranjos terão implicações diferentes em termos de promoção da equidade (CÁNEPA, 2003; DALY e FARLEY, 2004).

Desta forma, como as correntes neoclássicas enfocam fundamentalmente a questão da alocação eficiente, tendem a priorizar os instrumentos econômicos de criação de mercados, atrelados ao conceito coaseano, segundo o qual os agentes econômicos negociam entre si a alocação ótima dos recursos (incluindo pagamento de compensações pelo dano ambiental) com mínima participação do Estado (GUEDES e SEEHUSEN, 2011; MOTTA, 2006, 2011).

Já na perspectiva da economia ecológica, costuma-se argumentar que em muitos contextos é necessária maior participação do Estado, mesmo na implantação de instrumentos econômicos. Um dos pontos que embasam esta posição é a limitação dos mercados, e da presumida racionalidade individual dos atores que os compõem, para lidar com bens públicos e com interesses sociais que vão além de interesses econômicos, características definidoras de boa parte dos serviços ecossistêmicos (DALY, 1999; DALY e FARLEY, 2004; MARTINEZ-ALIER e ROCA JUSMET, 2001).

Outro argumento é o de que em diversas circunstâncias do mundo real os custos de transação ${ }^{7}$ envolvidos na implantação das condições para a existência do mercado e para as negociações entre os agentes serão elevados e, desta forma, os instrumentos de criação de mercado tendem a perder sua eficiência e pode-se chegar ao ponto em que nem mesmo as negociações entre as partes sejam viáveis (DALY, 1999; MARTINEZALIER e ROCA JUSMET, 2001; MAY, 2011).

Entretanto, é preciso considerar que, como destacam Common e Stagl (2005), diferentes instrumentos dão ênfase a diferentes objetivos de política ambiental, e não há um instrumento capaz de atingir igualmente objetivos de melhoria ambiental, redução de custos e aumento de equidade. Neste contexto, conforme argumentam Lustosa, Cánepa e Young (2003), atualmente tem se tornando mais comum a adoção de uma abordagem mista pelos elaboradores de políticas, com o uso de múltiplos instrumentos incluindo tanto regulação direta quanto instrumentos econômicos.

Além disso, os objetivos e a execução da política ambiental não são definidos apenas por meio do conhecimento teórico e científico. Eles são resultado de um processo político de negociação com os atores envolvidos e com a sociedade. Desta forma, não se pode esperar que os resultados obtidos pelo uso dos instrumentos serão necessariamente aderentes aos padrões necessários para garantir o ótimo econômico, como enfatiza a economia ambiental, nem a resiliência

7. Os custos de transação são todos os custos necessários para que as partes envolvidas em uma negociação cheguem a um acordo, incluindo tempo e recursos financeiros usados para a negociação, formalização e garantia de cumprimento do acordo (DALY e FARLEY, 2004). 
dos ecossistemas envolvidos e a distribuição equitativa de recursos, conforme ressalta a economia ecológica.

Neste contexto, ao buscar definir conceitualmente o REDD+ de forma mais específica, nota-se que, como argumentam Angelsen e McNeill (2012), o entendimento em relação ao REDD+ vem evoluindo ao longo dos últimos anos nas discussões internacionais. Mas, ao mesmo tempo, vem sofrendo um processo de ampliação, tornando-se uma ideia que atenderia a diversos interesses e que tem sido interpretada de formas diferentes por diferentes grupos, dependendo do contexto, dos objetivos e dos interesses de quem o está definindo. Esta pluralidade fica evidente ao considerarmos os diversos componentes (Quadro 1) a serem implantados como parte do REDD+.

Segundo a abordagem da UNFCCC, no âmbito do REDD+ serão incentivadas Atividades para a provisão dos serviços ambientais relacionados ao carbono. Mas também devem ser oferecidos incentivos para a implantação de outros Elementos, incluindo instrumentos regulatórios e arranjos institucionais, como estratégias nacionais, sistemas para Mensuração, Relato e Verificação (MRV) e para cumprimento de salvaguardas sociais e ambientais. Esta abordagem indica como no REDD+ convivem vários conceitos e instru- mentos direcionados ao incentivo e à viabilização de ações de REDD+, tais como desenho e implantação de instituições, políticas de comando e controle e instrumentos econômicos.

Nesse contexto, não há atualmente um consenso na literatura sobre uma definição conceitual precisa do REDD+. Wunder (2010, p. 30), por exemplo, comenta que um dos entendimentos possíveis para o REDD+ é considerá-lo como um sistema agente-principal. Já Skutsch (2011) defende que o REDD+ pode ser mais bem entendido como um mecanismo político de indução. Contudo, uma das abordagens mais comuns na literatura é a que discute o REDD + como instrumento de incentivo a partir do conceito de PSA (BÖRNER et al., 2010; CORBERA, 2012; HALL, 2013; LEDERER, 2011; MAHANTY, SUICH e TACCONI, 2013).

Os pagamentos por serviços ambientais, por sua vez, podem ser entendidos como um instrumento de criação de mercado em que indivíduos ou comunidades são pagos para oferecer um Serviço Ambiental (SA), isto é, para tomar ações que aumentem a provisão dos serviços ecossistêmicos desejados. Mais especificamente, de acordo com a definição clássica proposta por Wunder (2007), um PSA é um acordo voluntário entre ao menos um vendedor e um comprador para o for-

Quadro 1. Componentes do REDD+

\begin{tabular}{|l|l|}
\hline \multicolumn{1}{|c|}{ Componente } & \multicolumn{1}{c}{ Descrição } \\
\hline Atividades & $\begin{array}{l}\text { Atividades de mitigação florestal que serão incentivadas: } \\
\text { - Redução de emiscóes por desmatamento; } \\
\text { - Redução de emissões por degradação florestal; } \\
\text { - Conservação de estoques de carbono; } \\
\text { - Manejo sustentável das florestas; } \\
\text { - Aumento dos estoques de carbono. }\end{array}$ \\
\hline Elementos & $\begin{array}{l}\text { Elementos que devem ser elaborados e implantados pelos países, adicionalmente às atividades mencionadas } \\
\text { anteriormente: } \\
\text { - Estratégias ou planos de ação nacionais de REDD+, incluindo o tratamento de questões estruturais que } \\
\text { geram o desmatamento e degradação florestal; } \\
\text { - Nivel nacional de referência de emissões florestais ou de cobertura florestal; } \\
\text { - Sistema nacional de monitoramento e relato das atividades de REDD+; } \\
\text { - Sistema de informações sobre as salvaguardas para evitar resultados sociais e ambientais negativos das } \\
\text { iniciativas de REDD+. }\end{array}$ \\
\hline Fases & $\begin{array}{l}\text { Fases em que as atividades e elementos acima serão criados e implantados: } \\
\text { - Elaboração de estratégias nacionais, políticas e medidas para a adoção do REDD+, incluindo capacitação } \\
\text { dos atores envolvidos; } \\
\text { - Implantação destas estratégias e medidas, além da implantação de projetos piloto baseados em resultados; } \\
\text { - Adoção de projetos e ações de REDD+ baseadas em resultados, as quais devem ser totalmente Mensura- } \\
\text { das, Relatadas e Verificadas. }\end{array}$ \\
\hline Ações & $\begin{array}{l}\text { Projetos ou ações práticas por meio das quais as atividades e elementos abrangidos pelo REDD+ serão } \\
\text { implantados. }\end{array}$ \\
\hline Mecanismo & $\begin{array}{l}\text { Mecanismo de incentivo em si, com objetivo de fomentar e/ou viabilizar a implantação dos Elementos e das } \\
\text { Atividades de REDD+. }\end{array}$ \\
\hline
\end{tabular}

Fonte: Baseado em UNFCCC (2011). 
necimento de um SA bem definido ou de um uso da terra que presumidamente forneça este $\mathrm{SA}$, condicionado à garantia de que este serviço seja efetivamente prestado.

De acordo com este entendimento, o PSA é também um instrumento atrelado ao conceito coaseano, à medida que promove a negociação entre as partes afetadas como forma de corrigir externalidades. O PSA, portanto, busca internalizar as externalidades e deveria ser então aplicado aos casos específicos em que os ecossistemas não são bem geridos devido ao fato de que seus benefícios são externalidades do ponto de vista dos gestores destes ecossistemas (ENGEL, PAGIOLA e WUNDER, 2008).

Por isso a importância da definição de Wunder (2007) mencionada anteriormente, a qual garantiria as características necessárias para o estabelecimento da transação entre as partes. Assim, a "propriedade" pelos serviços ambientais precisa ser atribuída ao responsável pelos usos da terra que possibilitam a manutenção do ecossistema em condição de produzir estes serviços. Isso permitiria o estabelecimento de provedores (vendedores) e de beneficiários (compradores) da externalidade, que passam assim a negociar entre si o fornecimento do serviço em questão.

Ainda nessa perspectiva, é essencial no PSA que sejam considerados os fatores que afetam os custos de transação, tais como: a quantidade e o papel dos intermediários; e os esforços para a redução da assimetria de informações, incluindo a definição clara dos serviços transacionados e a mensuração, reporte e verificação dos resultados, de forma a garantir o cumprimento dos acordos (ENGEL, PAGIOLA e WUNDER, 2008).

Por outro lado, análises ligadas à corrente da economia ecológica apresentam um entendimento mais abrangente do conceito de PSA, como um mecanismo de incentivo econômico não necessariamente restrito à criação de mercados. Por exemplo, Muradian et al. (2010, p. 1205) definem o PSA como

"[...] a transfer of resources between social actors, which aims to create incentives to align individual and/or collective land use decisions with the social interest in the management of natural resources".

Assim, para Muradian e seus colaboradores (2010), a definição é mais abrangente e considera que as transferências poderiam ocorrer, por exemplo, por meio de um mercado ou de subsídios, e até mesmo serem oferecidas não em valores monetários, mas sim na forma de outros benefícios e bens públicos aos provedores. Nesta visão, o Estado pode assumir papel muito mais central na viabilização do PSA, seja como intermediário, seja por meio de intervenções para garantir a transferência de recursos

Jack, Kousky e Sims (2008) adotam perspectiva similar ao considerar que os esquemas de PSA são mecanismos baseados em incentivo, os quais podem por sua vez ser implantados por meio de pagamentos diretos aos produtores ou por meio de distintos instrumentos econômicos, tais como permissões negociáveis e subsídios diretos e indiretos. Convergem assim com Muradian et al. (2010, 2013), os quais defendem que os PSA incluem também outras formas de incentivo e que, na verdade, a maioria dos PSA existentes não seriam transações de mercado.

Desta forma, na concepção do PSA como criação de mercado admite-se que o instrumento pode ser implantado de maneira complementar a outros instrumentos de política, mas entende-se que o PSA propriamente dito trata de pagamentos diretos a partir do conceito coaseano. O PSA seria então parte de um policy mix ${ }^{8}$. (ANDRADE e FASIABEN, 2010; ENGEL, PAGIOLA e WUNDER, 2008). Já a concepção de PSA como um mecanismo de incentivo, ao considerá-lo como um conceito mais abrangente que objetiva incentivar e viabilizar a provisão de SA, aponta que o mesmo seja implantado por meio de um conjunto de instrumentos de incentivo, que pode ou não envolver transações coaseanas. O PSA seria então, em si mesmo, um policy mix (MURADIAN et al., 2010, 2013; SANTOS e VIVAN, 2012).

Esta diferenciação em relação ao PSA está, portanto, relacionada às distintas visões, mencionadas no início desta seção, sobre o papel dos instrumentos econômicos de política ambiental. A concepção de PSA em termos coaseanos atende à visão da economia ambiental neoclássica, de priorizar o envolvimento direto do mercado como forma de solução para os problemas ambientais. Já a visão de PSA como instrumento de

8. Expressão geralmente usada para indicar um conjunto de políticas ou um pacote de instrumentos de política usado para atingir determinados objetivos (ENGEL, PAGIOLA e WUNDER, 2008; SANTOS e VIVAN, 2012). No caso do PSA, o objetivo de manutenção ou ampliação da oferta de serviços ecossistêmicos. 
incentivo abre espaço para a inclusão de outros mecanismos que não dependam de transações de mercado, se aproximando mais da visão da economia ecológica sobre a importância das instituições e da participação do Estado na solução dos problemas ambientais (ANDRADE e SIMÕES, 2013).

A partir do debate sumarizado anteriormente, considerando que há diferentes perspectivas sobre a definição de PSA, certamente também haverá distintos entendimentos sobre o que significa o REDD+ ser um mecanismo que envolve o conceito de PSA.

Ao ser analisado a partir de uma perspectiva coaseana, o REDD+ seria um policy mix que inclui um instrumento de PSA. Esta é a perspectiva de Angelsen e Wertz-Kanounnikof (2008) ao afirmarem que, como parte do REDD+, estão previstas estratégias nacionais que incluem, além de um PSA, um amplo conjunto de políticas como: ordenamento fundiário, melhor gerenciamento de áreas protegidas, dentre outras. Nesta perspectiva, é central para o mecanismo a realização de transações de mercado por meio das quais será feito o pagamento para adoção das ações de REDD+.

Já analisando a partir de uma visão mais abrangente de PSA, tal como a defendida por Muradian et al. (2010), esta distinção não é tão clara. Como apresentado anteriormente, segundo esta conceituação o PSA seria um sistema de incentivo que pode utilizar-se de diversos instrumentos para incentivar a oferta dos SA definidos. Nesta perspectiva, podem ser adotados outros mecanismos para a transferência de recursos de forma a incentivar as ações de REDD+, com pouca ou nenhuma participação de transações de mercado.

Em ambos os pontos de vista, considerando a centralidade dos incentivos no REDD+, é essencial que estejam disponíveis recursos para viabilizar os incentivos aos provedores dos serviços ambientais. Por outro lado, diferentes modalidades de financiamento podem estar atreladas ao uso de diferentes instrumentos econômicos para a implantação do REDD+. Assim, modalidades de financiamento não são apenas as formas escolhidas para levantar recursos para o REDD+, mas também impactam e são impactadas pela própria estrutura do mecanismo, estando intimamente relacionadas aos entendimentos teórico-conceituais a partir do qual o REDD+ pode ser concebido e aplicado.

Fazem parte deste contexto os debates que vêm ocorrendo no meio acadêmico e na UNFCCC a respeito das modalidades de financiamento do REDD+
(VIANA, 2009), as quais podem ser definidas de maneira mais próxima ao conceito coaseano de PSA, isto é, com priorização de transações de mercado para SA bem definidos, ou de maneira mais abrangente, abrindo espaço para adoção de diferentes instrumentos como forma de incentivo ao provimento dos serviços ambientais, tais como o financiamento público e a adoção de políticas governamentais.

\section{Metodologia}

Para atingir os objetivos propostos, foi realizada pesquisa documental em fontes secundárias sobre projetos de REDD+ para a coleta de dados, os quais foram em seguida analisados utilizando-se estatística descritiva e testes de hipóteses, de forma a identificar e descrever de forma exploratória as características dos projetos de REDD+ existentes no Brasil e avaliar a relação entre estas características e as modalidades de financiamento adotadas pelos projetos, via fundos públicos ou via mercado.

A estratégia adotada para a pesquisa documental foi a de consulta de dados e documentos disponibilizados pelos projetos aos seus financiadores, disponíveis em bases de dados de acesso público especializadas neste tipo de projeto. A coleta de dados ocorreu no período de janeiro a outubro de 2015, por meio de acesso direto aos endereços eletrônicos das seguintes bases': Fundo Amazônia; Markit e APX.

Estas bases foram escolhidas por disponibilizarem seus dados publicamente e por sua relevância para a centralização de dados de projetos, provavelmente devido ao papel central que possuem na relação dos projetos com seus financiadores. Na modalidade de fundos públicos, a base faz parte do processo de avaliação de projetos e concessão de recursos do FA, o qual é responsável pela mobilização da maioria do financiamento a REDD+ no Brasil (SILVA-CHÁVEZ, SCHAAP e BREITFELLER, 2015). Já na modalidade de mercado, a Markit e a APX atuam como os principais sistemas de

9. As bases podem ser acessadas nos seguintes endereços eletrônicos. FA: < http://www.fundoamazonia.gov.br/Fundo Amazonia/fam/site_pt/Esquerdo/Projetos_Apoiados/ Carteira_Projetos $>$; Markit Environmental Registry: $<$ https://mer.markit.com/br-reg/public/index.jsp?s=ca $>$; APX: < <ttps://vcsregistry2.apx.com/myModule/rpt/ myrpt.asp?r=111> e <https://acr2.apx.com/myModule/ rpt/myrpt.asp?r=111>. Acesso em: 14 fev. 2016. 
registro do MVC (GOLDSTEIN e GONZALEZ, 2014), viabilizando a compra e a venda dos créditos de carbono, forma pela qual estes projetos obtêm recursos.

Com isto, a unidade de análise da pesquisa (FRANKFORT-NACHMIAS e NACHMIAS, 2008) são os projetos de REDD+, e os critérios utilizados para a seleção dos projetos analisados são: 1) projetos registrados nas bases de acesso público mencionadas anteriormente; 2) relacionados às Atividades e Elementos de REDD+ (Quadro 1); 3) localizados totalmente ou em parte no território brasileiro e 4) já aprova$\operatorname{dos}^{10}$ no âmbito de suas respectivas modalidades de financiamento.

Para organizar e descrever as características dos projetos, a análise dos dados é feita considerando as 18 variáveis a seguir: A. Modalidade de financiamento; B. Status do projeto; C. Tempo entre início e aprovação; D. Tempo entre aprovação e recursos; E. Tempo entre início e recursos; F. Natureza jurídica do proponente; G. Abrangência geográfica do projeto; H. Prazo de execução; I. Condicionalidade do pagamento; J. Metodologia pré-definida; K. Contabilização de emissões; L. Divulgação do custo do projeto; M. Divulgação dos recursos recebidos; N. Auditoria; O. Tipo de relatório publicado; P. Componente(s) de REDD+; Q. Estratégias para promoção das Atividades; R. Estratégias para promoção dos Elementos.

A escolha das variáveis buscou descrever os projetos a partir de temas referenciados como relevantes na literatura sobre REDD+ e sobre instrumentos econômicos de política ambiental: agilidade para a concessão do incentivo; atores envolvidos nos projetos; abrangência temporal e geográfica dos projetos; critérios para concessão de incentivos, ações práticas a serem implementadas e formas de mensuração, relato e verificação das ações e dos resultados obtidos (p. ex. CACHO, LIPPER e MOSS, 2013; DUCHELLE et al., 2014; ENGEL, PAGIOLA e WUNDER, 2008; FOSCI, 2013; MURADIAN et al., 2010; SKUTSCH et al., 2011; VIANA, 2009; WUNDER, 2007).

Os dados referentes às variáveis foram obtidos diretamente das bases consultadas. Especificamente em relação à caracterização das diversas ações práticas

10. No caso do Fundo Amazônia, que estejam contratados ou ao menos já aprovados para recebimento de recursos. No caso do mercado, que tenham créditos verificados ou ao menos já tenham sido validados pelos respectivos padrões do mercado. adotadas pelos projetos, tomou-se como ponto de partida a classificação prevista pela UNFCCC (2011) sobre os componentes que devem ser incentivados pelo mecanismo de REDD+ (Quadro 1), incluindo o detalhamento das Atividades e dos Elementos promovidos. Para isso, foram consideradas as informações qualitativas disponíveis nas bases de dados, como a descrição dos objetivos e das ações promovidas pelos projetos.

Para análise dos dados coletados foi utilizada estatística descritiva e testes estatísticos de hipóteses (LEVIN e FOX, 2004). As análises foram feitas considerando-se todos os projetos existentes no Brasil sob o FA e o MVC, isto é, o que pode ser considerada em termos estatísticos a atual população destas duas iniciativas específicas. Contudo, estas iniciativas não necessariamente representam todos os projetos de REDD+ existentes no Brasil e nem podem ser igualadas às modalidades de financiamento em si, ou seja, elas são apenas uma prévia da forma como poderia se configurar posteriormente o mecanismo de REDD+ sob cada modalidade a partir da Fase III prevista pela UNFCCC (Quadro 1).

Tem-se, então, que o procedimento de amostragem adotado não é probabilístico, mas sim determinístico por julgamento. Nesta situação a amostra é selecionada a partir do conhecimento e julgamento do pesquisador (FRANKFORT-NACHMIAS e NACHMIAS, 2008; LEVIN e FOX, 2004). Entende-se que tal escolha é adequada e considera ambas as modalidades de financiamento, pois, como mencionado anteriormente, FA (SILVA-CHÁVEZ, SCHAAP e BREITFELLER, 2015) e MVC (GOLDSTEIN e GONZALEZ, 2014; HAMRICK, 2015) são relevantes para o mecanismo de REDD+ no Brasil, tanto em termos de números de projetos quanto de montante de recursos alocados sob cada modalidade.

Desta forma, foram realizados testes estatísticos para duas amostras, definidas a partir da modalidade de financiamento adotada pelos projetos. Assim, foram avaliadas as variáveis que descrevem as características dos projetos sempre em relação à variável modalidade de financiamento (Variável A). Para isto foram aplicados os testes estatísticos Mann-Whitney e Quiquadrado para diferença entre medianas e para associação entre as variáveis, respectivamente.

Para as variáveis quantitativas (intervalares), como as que representam os prazos, o número de estados abrangidos e o prazo de duração de projetos, foi 
utilizado o teste não paramétrico de Mann-Whitney. Este teste busca avaliar eventuais diferenças entre as medianas da variável em questão para projetos do mercado e de fundo público, sendo adequado quando a variável não apresenta uma distribuição normal (CONOVER, 1999).

Já para as variáveis qualitativas ordinais e nominais, como pretende-se avaliar se as características dos projetos estão associadas à modalidade de financiamento adotada, foi usado o teste Qui-quadrado de forma a verificar se existe ou não associação entre as duas variáveis. Assim, foram realizados testes de independência usando a estatística Qui-quadrado ( $\chi 2)$, considerada adequada para avaliar, nas tabelas de dupla entrada, se a variável em questão está ou não relacionada ao uso de financiamento público ou via mercado (CONOVER, 1999; FRANKFORT-NACHMIAS e NACHMIAS, 2008). Para todos os testes acima mencionados adotou-se um nível de significância $\alpha=0,05$.

\section{Características dos projetos de REDD+ sob distintas modalidades de financiamento}

Até a data de corte para o levantamento de informações da presente pesquisa, em outubro de 2015, foram identificados 89 projetos de REDD+ nas bases de dados pesquisadas. A maior parte está sendo financiada pela modalidade de fundos públicos, totalizando 74 projetos $(83 \%)$. Os financiados pela modalidade de mercado somam 15 projetos $(17 \%)$.

As Tabelas 1, 2 e 3 buscam sintetizar, de forma ilustrativa, as características identificadas para os projetos pelas variáveis de análise em relação à Modalidade de financiamento (Variável A). A Tabela 1 consolida os resultados das variáveis escalares, buscando oferecer uma visão sobre a duração dos projetos e a agilidade na concessão de recursos aos mesmos. Também apresenta o respectivo p-valor calculado pelo teste de Mann Whitney, para identificar diferenças entre as medianas apresentadas pelos projetos sob cada modalidade.

A Tabela 2 consolida os resultados das variáveis nominais mais ligadas ao desenho dos projetos e o respectivo p-valor calculado pelo teste Qui-quadrado, buscando identificar independência entre projetos de fundo público e projetos de mercado. Nesta tabela, para cada variável em que houve diferença estatis- ticamente significativa, foi indicada a característica preponderante ${ }^{11}$ apresentada pelos projetos sob cada modalidade. Para as variáveis em que não houve diferença estatisticamente significativa é apresentada a característica preponderante para a amostra como um todo.

Já a Tabela 3 apresenta as variáveis nominais ligadas à implantação prática dos projetos, descrevendo os Elementos e as Atividades de REDD+ promovidos pelos projetos. Da mesma forma, é apresentado o p-valor calculado pelo teste Qui-quadrado, buscando identificar independência entre projetos de fundo público e projetos de mercado. Contudo, para estas variáveis que descrevem as estratégias de implantação de Elementos e Atividades, vale lembrar que nem todos os projetos têm atuação em todas as estratégias, e aqueles que atuam podem usar uma ou mais estratégias simultaneamente. Desta forma, as somas do número de projetos atuando nas estratégias são diferentes do número total de projetos atuando no respectivo Elemento ou Atividade.

Seguindo a lógica mencionada na seção 2, a discussão das variáveis está organizada a partir de questões consideradas centrais para estruturação e análise do REDD+, tanto na perspectiva coaseana quanto na perspectiva abrangente sobre o mecanismo. São elas: agilidade para concessão de incentivos, atores envolvidos; critérios adotados para a concessão do incentivo; ações práticas que serão efetivamente incentivadas.

Em relação à agilidade para concessão de incentivos, notou-se que para os Projetos financiados pelo Mercado de Carbono (PMC) transcorre um período muito superior de Tempo entre início e aprovação (Variável C), denotando que é necessário um considerável grau de estruturação e amadurecimento do projeto até que esteja em condições de ser apresentado para aprovação no MVC. Por outro lado, no Fundo Amazônia o início oficial do projeto ocorre somente após aprovação e contratação pelo BNDES. Assim, o valor da Variável C dentre os Projetos financiados via Fundo Público (PFP) é negativo e, mesmo agregando-se o Tempo entre aprovação e recebimento dos recursos (Variável D), o prazo total

11. As características apresentadas na Tabela 2, por serem oriundas das variáveis nominais, referem-se às categorias que apresentaram maior frequência para cada variável. Quando mais de uma característica apresentou frequência expressiva, ou quando houve características com frequências semelhantes, ambas foram incluídas. 
considerando o Tempo entre início do projeto e o recebimento dos recursos (Variável E) para os PFP é sensivelmente menor do que para os PMC.

Apesar do argumento apresentado por Marcovitch e Pinsky (2014) de que o processo de análise e aprovação de projetos do FA é excessivamente complexo e implica em custos de transação, a avaliação conjunta da ausência de relação estatisticamente significativa entre as modalidades quanto ao Status dos projetos (Variável $B)$ e da maior celeridade no processo de aprovação fornece indícios consistentes de que o Fundo Amazônia tem sido eficiente na aprovação e repasse de recursos aos projetos quando comparado ao MVC. Esta situação também não corrobora, dentre os projetos analisados, a suposta maior eficiência dos mecanismos de mercado, muitas vezes considerada uma premissa pelas correntes neoclássicas. Conforme apontado por Jack,
Kousky e Sims (2008) e por Wunder (2013), esta eficiência dependerá fundamentalmente das regras estabelecidas pelos mecanismos e do contexto de implantação.

Em relação aos Atores Envolvidos, pode-se notar que, em termos da Natureza jurídica do proponente (Variável F), há certa complementaridade entre os perfis dos projetos sob cada modalidade, e em ambas há uma lacuna de participação de atores. Os PFP não possuem proponentes da iniciativa privada e nos PMC há baixa participação da administração pública e do terceiro setor. Entretanto, a partir da avaliação qualitativa dos proponentes durante a coleta de dados, percebeu-se que projetos sob ambas as modalidades geralmente não são propostos diretamente pelos usuários da terra, mas sim por intermediários, tais como ONGS, associações ou proprietários não diretamente envolvidos nas atividades produtivas.

Tabela 1. Características dos projetos piloto de REDD+ (variáveis escalares), sob cada modalidade de financiamento

\begin{tabular}{lccc}
\hline \multirow{2}{*}{ Variável } & \multicolumn{2}{c}{ Características preponderantes } & \multirow{2}{*}{ p-valor } \\
\cline { 2 - 3 } & Proj. Fundo Público & Proj. Mercado & \\
\hline C. Tempo entre início e aprovação & $-3,3$ meses & 42,8 meses & 0,000 \\
D. Tempo entre aprov. e recursos & 8,2 meses & 10,3 meses & 0,736 \\
E. Tempo entre início e recursos & 4,02 meses & 56,7 meses & 0,000 \\
H. Prazo de execução & 3,0 anos & 30,0 anos & 0,000 \\
\hline
\end{tabular}

Fonte: Elaboração própria com base nos resultados da pesquisa.

Tabela 2. Características dos projetos piloto de REDD+ (variáveis nominais), sob cada modalidade de financiamento

\begin{tabular}{|c|c|c|c|}
\hline \multirow{2}{*}{ Variável } & \multicolumn{2}{|c|}{ Características preponderantes } & \multirow{2}{*}{ p-valor } \\
\hline & Proj. Fundo Público & Proj. Mercado & \\
\hline B. Status do projeto & \multicolumn{2}{|c|}{ Recebendo recursos $(68,54 \%)$} & 0,378 \\
\hline F. Natureza jurídica do proponente & $\begin{array}{l}\text { Administração pública }(52,7 \%) \\
\text { Terceiro setor }(47,3 \%)\end{array}$ & $\begin{array}{l}\text { Empresa privada }(80 \%) \\
\text { Terceiro setor }(13,33 \%)\end{array}$ & 0,000 \\
\hline G. Abrangência geográfica & $\begin{array}{l}\text { Abrangente }(55,41 \%) \\
\text { Supraterritorial }(41,89 \%)\end{array}$ & Restrita $(100 \%)$ & 0,000 \\
\hline I. Condicionalidade do pagamento & Com base em esforços $(93,24 \%)$ & Com base em resultado $(100 \%)$ & 0,000 \\
\hline J. Metodologia pré-definida & Sem metodologia pré-definida $(100 \%)$ & $\begin{array}{l}\text { Emissões + cobenefícios }(60 \%) \\
\text { Emissões }(40 \%)\end{array}$ & 0,000 \\
\hline K. Contabilização de emissões & Não $(100 \%)$ & $\operatorname{Sim}(100 \%)$ & 0,000 \\
\hline L. Divulgação do custo & Valor total relatado $(100 \%)$ & Valor não relatado $(86,67 \%)$ & 0,000 \\
\hline M. Divulgação dos recursos recebidos & Valor total relatado $(100 \%)$ & Valor não relatado $(100 \%)$ & 0,000 \\
\hline N. Auditoria & Acompanhamento pelas partes envolvidas $(100 \%)$ & Auditoria independente $(93,33 \%)$ & 0,000 \\
\hline O. Tipo de relatório publicado & Resumo descritivo $(98,65 \%)$ & Documentos detalhados $(100 \%)$ & 0,000 \\
\hline
\end{tabular}

Fonte: Elaboração própria com base nos resultados da pesquisa. 
Tabela 3. Atividades e Elementos implantados pelos projetos piloto de REDD+, sob cada modalidade de financiamento

\begin{tabular}{|c|c|c|c|c|}
\hline \multirow{2}{*}{\multicolumn{2}{|c|}{ Variável }} & \multicolumn{2}{|c|}{ Características preponderantes } & \multirow{2}{*}{ p-valor } \\
\hline & & Proj. Fundo Público & Proj. Mercado & \\
\hline \multicolumn{2}{|c|}{ P. Componentes de REDD+ promovidos } & $\begin{array}{c}\text { Elementos }(40,54 \%) \\
\text { Ativid. + Elementos }(37,84 \%)\end{array}$ & $\begin{array}{l}\text { Ativid. + Elementos }(66,67 \%) \\
\text { Atividades }(33,33 \%)\end{array}$ & 0,010 \\
\hline \multirow{6}{*}{$\begin{array}{l}\text { Q. } \\
\text { Atividades }\end{array}$} & $\begin{array}{l}\text { Q1. Técnicas e ativid. agrícolas mais } \\
\text { sustentáveis }\end{array}$ & $\operatorname{Sim}(41,89 \%)$ & $\operatorname{Sim}(73,33 \%)$ & 0,026 \\
\hline & $\begin{array}{l}\text { Q2. Recuperação de áreas degradadas } \\
\text { e desmatadas }\end{array}$ & \multicolumn{2}{|c|}{$\operatorname{Sim}(33,71 \%)$} & 0,572 \\
\hline & $\begin{array}{l}\text { Q3. Extrativismo, prod. não madeirei- } \\
\text { ros e ativ. alternativas }\end{array}$ & $\operatorname{Sim}(47,30 \%)$ & $\operatorname{Sim}(80,00 \%)$ & 0,021 \\
\hline & $\begin{array}{l}\text { Q4. Manejo sustentável p/ exploração } \\
\text { madeireira }\end{array}$ & \multicolumn{2}{|c|}{$\operatorname{Sim}(17,98 \%)$} & 0,337 \\
\hline & $\begin{array}{l}\text { Q5. Florestamento / reflorestamento } \\
\text { comercial }\end{array}$ & $\operatorname{Sim}(1,35 \%)$ & $\operatorname{Sim}(26,27 \%)$ & 0,000 \\
\hline & $\begin{array}{l}\text { Q6. Monitoramento local de áreas flo- } \\
\text { restadas }\end{array}$ & $\operatorname{Sim}(16,22 \%)$ & $\operatorname{Sim}(86,67 \%)$ & 0,000 \\
\hline \multirow{3}{*}{$\begin{array}{c}\mathrm{R} . \\
\text { Elementos }\end{array}$} & $\begin{array}{l}\text { R1. Ordenamento territorial e fundi- } \\
\text { ário }\end{array}$ & \multicolumn{2}{|c|}{$\operatorname{Sim}(43,82 \%)$} & 0,807 \\
\hline & R2. Governança florestal & \multicolumn{2}{|c|}{$\operatorname{Sim}(52,81 \%)$} & 0,098 \\
\hline & $\begin{array}{l}\text { R3. Desenvolvimento científico e tec- } \\
\text { nológico }\end{array}$ & \multicolumn{2}{|c|}{$\operatorname{Sim}(23,60 \%)$} & 0,759 \\
\hline
\end{tabular}

Fonte: Elaboração própria com base nos resultados da pesquisa.

Por um lado, a presença do Estado e de outros intermediários representando os beneficiários dos serviços ambientais é prevista pela economia ambiental neoclássica em PSA envolvendo serviços com características de bens públicos (ENGEL, PAGIOLA e WUNDER, 2008). Por outro, a falta de usuários da terra dentre os proponentes corrobora o papel central atribuído aos intermediários na visão abrangente de PSA, segundo a qual estes intermediários têm papel central no REDD+ para conectar usuários da terra a financiadores, e têm grande influência na formatação dos incentivos e na redução de custos de transação (SKUTSCH et al., 2011).

Esta observação também está relacionada ao papel que estes intermediários podem ter para a redução de custos de transação, de modo a viabilizar transações de mercado no nível de projetos (ENGEL, PAGIOLA e WUNDER, 2008; JACK, KOUSKY e SIMS, 2008). Assim, como afirmam Cacho, Lipper e Moss (2013), passa a ser central avaliar a necessidade de agrupamento de propriedades e de uso de infraestrutura física, gerencial e institucional já existentes para viabilizar estas transações.

Outro desafio que se apresenta a partir desta constatação está relacionado ao direito de propriedade. Para o estabelecimento de transações coaseanas, é necessário que o direito de propriedade pela externalidade positiva (no caso os serviços ambientais) seja claro e esteja alocado aos provedores, de forma que estes possam negociar e receber a remuneração pelo serviço gerado (COASE, 1960; ENGEL, PAGIOLA e WUNDER, 2008). Desta forma, as amplas deficiências de regularização fundiária existentes no Brasil (DUCHELLE et al., 2014; LAPOLA et al., 2013) podem elevar os custos de transação (WUNDER, 2007) e restringir a eficiência das transações de mercado. A existência de intermediários implica, então, em atores adicionais a serem considerados e que podem disputar a alocação de direitos de propriedade, ampliando as complexidades já existentes sobre o tema.

Em relação aos critérios adotados para a concessão dos incentivos em nível dos projetos, a Condicionalidade do pagamento (Variável I) adotada indica que os PMC são remunerados com base em resultados e os PFP prioritariamente com base em esforços, isto é, com base na adoção de ações que buscam atingir os objetivos ambientais, e não com base nos resultados efetivamente atingidos.

$\mathrm{O}$ critério de pagamento com base em resultados contribui para a redução da assimetria de informações e, consequentemente, dos custos de transação, já que o SA incentivado é mensurado e os recursos só são concedidos ao projeto mediante o cumprimento do acordo. 
Busca-se, assim, garantir a condicionalidade e a adicionalidade, centrais para o estabelecimento de transações coaseanas (ANDRADE e SIMÕES, 2013; ENGEL, PAGIOLA e WUNDER, 2008). Além disso, de forma equivalente ao comércio de permissões (CÁNEPA, 2003; COMMON e STAGL, 2005), ao atrelar os pagamentos à comprovação de resultados os PMC buscam estimular a eficiência, já que os projetos seriam propostos apenas por provedores com menores custos de redução de emissões (inferiores ao preço pago pelo mercado).

Os projetos de mercado concentram-se, então, em garantir que sejam atingidos resultados em termos de emissóes. $\mathrm{O}$ uso deste critério traz a vantagem de incentivar o uso eficaz dos recursos, possibilitando maior confiança de que o serviço ambiental em questão está sendo efetivamente provido (SKUTSCH et al., 2011). Porém, o critério não garante que a obtenção de tais resultados será feita necessariamente de forma equitativa e respeitando os direitos e necessidades dos envolvidos.

Já entre os PFP, como os recursos são concedidos a partir de esforços, o custo levado em consideração é o de executar determinadas ações e não o de se atingir determinado resultado em termos de $\mathrm{CO}_{2}$. Este critério está em linha com a visão geralmente presente entre os economistas ecológicos, que consideram os instrumentos econômicos como indutores de comportamento, não necessariamente buscando internalizar as externalidades diretamente via sistema de preços (DALY, 1999; MARTINEZ-ALIER e ROCA JUSMET, 2001).

Desta forma, dentre os PFP, a princípio, não há mecanismos específicos para levar em consideração as diferenças de custo para provisão dos serviços, reduzindo os estímulos para a busca de eficiência presentes nos PMC. Por outro lado, os PFP muitas vezes trabalham para reduzir os custos que os usuários da terra teriam para adotar ações de REDD+, utilizando para isso ações de política pública e de melhoria nas condições de mercado para produtos oriundos de agricultura e manejo sustentável.

Contudo, a adoção de um sistema de pagamento com base em esforços reforça a importância de que a gestão do FA adote um processo criterioso para a aprovação de projetos de modo a evitar uso ineficiente de recursos, já que para receber os recursos os projetos não precisarão demonstrar os resultados finais em termos de emissões, ou mesmo de outros efeitos ambientais das ações implantadas.
O fato de que os PMC são remunerados com base em resultados e os PFP, prioritariamente, com base em esforços, está alinhado às preocupações neoclássicas, no caso dos PMC, de que projetos sejam eficazes no uso dos recursos para obter resultados ambientais. E com as preocupações da economia ecológica, no caso dos PFP, para que os resultados dos projetos não sejam obtidos em detrimento de preocupações em relação à equidade e ao respeito a direitos das populações locais.

A adoção de critérios com base em esforços ou com base em resultados também pode estar relacionada à abrangência dos projetos, tanto em termos temporais quanto geográficos. Os PMC têm Prazo de execução (Variável H) muito mais longo que os PFP, facilitando, assim, as transações de mercado, já que aumentam assim a credibilidade e a estabilidade na provisão de SA, o que pode contribuir para permanência dos resultados, e também permite aos proponentes recuperar o capital inicial investido na estruturação do projeto.

Os PMC também são mais bem delimitados em termos de Abrangência geográfica (Variável G), de forma coerente com os critérios de concessão de incentivo por eles adotados. A maior circunscrição facilita a mensuração de resultados in loco e está em linha com as preocupações de proponentes de PSA de inspiração coaseana, já que a definição de contornos claros sobre os serviços sendo ofertados, incluindo os provedores e o local em que estes serviços são gerados, é importante para seu caráter custo-efetivo (ENGEL, PAGIOLA e WUNDER, 2008).

Por outro lado, esta diferença reforça a posição dos críticos de uma abordagem centrada unicamente em projetos locais para o REDD+ (NORGAARD, 2010), já que, ao considerar as vastas extensões de florestas que precisam ser conservadas, parece não ser viável que o mecanismo foque apenas em projetos locais de mercado baseados em padrões estritos, como ocorre no MVC. Este tipo de projeto pode ter um papel complementar, mas dificilmente terá capacidade de atingir a escala de alteração de uso do solo necessária para que o REDD+ seja um instrumento relevante de mitigação.

Além da abrangência dos projetos, aspectos relativos a MRV podem ter ampla inter-relação com os critérios adotados para concessão dos incentivos. Por exemplo, os PMC adotam Metodologias pré-definidas (Variável J) e fazem a Contabilização de resultados em termos de emissões (Variável K). Já os PFP, apesar da existência de diretrizes gerais do Comitê Orientador do 
Fundo Amazônia (COFA) e do BNDES, não contam com metodologia detalhada e não contabilizam seus resultados em termos de emissões reduzidas.

Estes perfis são coerentes com os critérios de concessão de incentivos das iniciativas. Para os PMC, em linha com as bases dos instrumentos coaseanos, são necessárias metodologias que normatizem e padronizem regras para aferição de resultados em termos de SA, de forma a gerar as condições de transação dos serviços, e consequente pagamento por estes resultados (MINANG e VAN NOORDWIJK, 2013). A não adoção de metodologias pelos PFP pode ajudar a reduzir os custos de transação com MRV, já que a mensuração não é feita individualmente em cada projeto e sim em âmbito nacional. Por outro lado, a falta de metodologias dificulta a elaboração e aprovação de projetos, bem como aumenta o risco de projetos não serem efetivos (MARCOVITCH e PINSKY, 2014) e também pode majorar os custos de transação (CACHO, LIPPER e MOSS, 2013).

Ainda em relação a $\mathrm{MRV}$, as práticas relacionadas ao nível de transparência, distintas entre os dois perfis de projetos, também podem ser entendidas a partir dos critérios de concessão do incentivo. Por um lado, os PMC tornam públicas informações muito mais completas e detalhadas (Variável O - Tipo de relatório publicado), além de passarem obrigatoriamente por auditorias independentes (Variável $N$ - Auditoria), o que não ocorre com os PFP. Em compensação, ao contrário dos PFPs, os PMC não fazem a Divulgação dos custos do projeto (Variável L) e nem a Divulgação dos recursos recebidos (Variável M).

Por outro lado, em alguns pontos-chave os contrastes entre os perfis não se mostraram tão claros, como no caso das ações práticas adotadas pelos projetos. Apesar de terem sido identificadas diferenças iniciais no padrão de envolvimento dos projetos com os Componentes de REDD+ promovidos (Variável P), ambas as categorias de projetos atuam tanto em Elementos quanto em Atividades.

Notou-se que tanto os PFP como os PMC possuem atuação nas diversas Estratégias para promoção dos Elementos (Variável R). Por outro lado, durante a coleta e interpretação dos dados, foi possível identificar claramente diferenças qualitativas na forma como os projetos em cada modalidade de financiamento lidam com estes Elementos.

Os PMC, por serem majoritariamente realizados por proponentes da iniciativa privada, atuam de forma complementar em termos de implantação e fortalecimento de instituições e políticas públicas, contribuindo marginalmente para os Elementos. Assim, esta atuação é por vezes considerada como um cobenefício nestes projetos. Já entre os PFP, por terem maior participação de ONGs e principalmente do Estado entre seus proponentes, esta atuação é mais central, com muitos projetos assumindo papel direto na criação de instituições e na elaboração ou implantação de políticas públicas.

Um dos exemplos mais claros desta situação pode ser observado nos projetos que atuam em termos de ordenamento territorial e fundiário. A maioria dos PMC que promovem esta estratégia o faz à medida que os proponentes se comprometem a incentivar e cooperar com a concessão de títulos de propriedade às comunidades tradicionais e demais moradores que habitam a área do projeto. Já os PFP costumam ter papel mais central, com projetos que apoiam a implantação do Cadastro Ambiental Rural (CAR) em regiões que vão desde municípios até estados inteiros. Além disso, alguns destes PFP atuam também em relação à estratégia de governança florestal por meio da criação ou fortalecimento de ferramentas ligadas ao CAR, como a elaboração de bases cartográficas, metodologias de mapeamento fundiário, e módulos complementares do Sistema de Cadastro Ambiental Rural (Sicar).

Ainda assim, a falta de associação estatisticamente significativa entre as diversas estratégias adotadas sob cada modalidade contrapõe a premissa assumida em estudos (FOSCI, 2013a; THOMPSON, BARUAH e CARR, 2011) de que projetos de mercado, baseados em resultados, estariam atrelados apenas aos usos da terra, não contribuindo para a implantação de políticas. Como os projetos de mercado necessitam de um ambiente regulatório robusto, por exemplo com direitos de propriedade bem definidos, faz sentido que sejam impelidos a colaborar e participar na implantação destas políticas em locais que apresentem lacunas institucionais e de enforcement regulatório. Com isso, mesmo considerando as diferenças qualitativas mencionadas acima, pode-se considerar que os PMC contribuem para o fortalecimento de instituições e para a implantação e cumprimento de políticas públicas.

Observamos situação análoga para as Estratégias para promoção das Atividades (Variável Q) em relação às quais projetos sob ambas as modalidades possuem atuação consistente. Assim, como esperado, os PMC possuem forte presença nesta variável, apresentando 
atuação mais frequente do que os PFP em quatro das seis estratégias. Considerando que, como denotam os resultados da Variável G, os PMC são projetos territorialmente melhor delimitados, faz sentido que apresentem maior participação nas estratégias mais diretamente ligadas aos usos da terra.

Contudo, os PFP também se mostraram atuantes, com presença de projetos atuando em todas as estratégias. A falta de diferença estatisticamente significativa em relação à recuperação de áreas degradadas (Q2) provavelmente está atrelada ao impacto da política de regularização ambiental rural atualmente em curso no Brasil, com a implantação do novo código florestal. Assim, tanto os proprietários de terra locais quanto as organizações do terceiro setor e da administração pública estão fortemente envolvidos neste processo. É notório, por exemplo, o grande envolvimento dos PFP analisados na implantação do CAR e de Sistemas de Integração Lavoura Pecuária Floresta, preconizados pelo Plano $\mathrm{ABC}^{12}$.

Já a baixa atuação dos PFP e PMC em manejo sustentável para exploração madeireira pode estar atrelado à grande dificuldade ainda existente no Brasil para superar o fornecimento generalizado de madeira oriunda de desmatamento ilegal (MCDERMOTT, IRLAND e PACHECO, 2015).

Em esquemas de PSA podem existir etapas intermediárias entre a origem dos recursos e os seus destinatários finais (MURADIAN et al., 2010; SKUTSCH et al., 2011). Esta mesma situação é reconhecida no REDD+, especialmente devido à característica global do serviço prestado, o que aumenta a distância máxima possível entre beneficiários/financiadores do serviço e os vários atores locais responsáveis pela preservação, manejo e recuperação das florestas, estando ambos espalhados ao redor do globo (ANGELSEN e WERTZ-KANOUNNIKOFF, 2008; CACHO, LIPPER e MOSS, 2013; SKUTSCH et al., 2011).

Assim, dentro de cada projeto, os proponentes muitas vezes não são os atores que estão realizando

12. O Plano Setorial de Mitigação e de Adaptação às Mudanças Climáticas para a Consolidação de uma Economia de Baixa Emissão de Carbono na Agricultura, também denominado de Plano ABC (Agricultura de Baixa Emissão de Carbono), tem por finalidade a organização e o planejamento das ações a serem realizadas para a adoção das tecnologias de produção sustentáveis no setor agropecuário (Disponível em: <http://www.agricultura.gov.br/desenvolvimento-sustentavel/plano-abc >. Acesso em: 14 fev. 2016. diretamente as alterações no uso da terra, mas, sim, atores intermediários. Os proponentes podem, então, aplicar as estratégias diretamente ou adotar ações junto aos agentes finais (tais como proprietários da terra, comunidades tradicionais, agricultores etc.) para que estes implantem as estratégias de uso do solo. Com isso, em relação às atividades foi feito ainda um desdobramento das ações utilizadas pelos projetos para cada uma das estratégias Q1 a Q6, buscando detalhar as formas por meio das quais estas estratégias são implantadas.

Considerando que nem todos os projetos têm atuação em todas as estratégias, que aqueles que atuam podem usar uma ou mais ações para cada estratégia e que as ações adotadas podem ser as mesmas para diferentes estratégias, a Tabela 4, a seguir, descreve o número de vezes que um projeto utilizou determinada categoria de ação ao menos uma vez, independente da estratégia a que esta ação esteja atrelada. Com isso, na Tabela 4 são mostradas as porcentagens de projetos que utilizam a ação para cada modalidade e para a amostra como um todo, não sendo possível totalizar $100 \%$ nem nas linhas e nem nas colunas.

Assim, é possível avaliar a quais tipos de ação os projetos mais recorrem como forma de implantar alguma das estratégias relacionadas às Atividades. Observa-se que a ação mais utilizada foi a de capacitação e assessoria técnica, adotada por $60 \%$ dos projetos, seguida de atuação direta do proponente, presente em $48 \%$ dos projetos.

Dentre os cinco tipos de ação houve diferença estatisticamente significativa entre PMC e PFP em três delas: Atuação direta do proponente; Capacitação e assessoria técnica e Pagamento a atores locais. Todas as três ações foram mais utilizadas pelos PMC do que pelos PFP. Por um lado, a maior proporção dos PMC que adotam a Atuação direta do proponente (93\%, contra $39 \%$ dentre os PFP) e o Pagamento a atores locais $(26 \%$, contra $6 \%$ dentre os PFP) reforça características coaseanas deste tipo de projeto. Os proponentes estão mais diretamente envolvidos com a consecução de algumas das estratégias e utilizam-se mais de pagamentos monetários para incentivar as mudanças no uso da terra.

De outro lado, ambos PMC e PFP possuem atuação no fortalecimento de instituições locais e no desenvolvimento de mercados e cadeias produtivas, ações que geralmente não ficam a cargo dos mercados e 
Tabela 4. Consolidação das ações adotadas para consecução das estratégias de promoção às Atividades (Q1 a Q6), sob cada modalidade de financiamento

\begin{tabular}{lccccccc}
\hline \multicolumn{1}{c}{ Ação } & \multicolumn{2}{c}{ Proj. F. público } & \multicolumn{2}{c}{ Proj. Mercado } & \multicolumn{2}{c}{ Todos os projetos } & \multirow{2}{*}{ p-valor } \\
\cline { 2 - 6 } & $n$ & $\%$ & $n$ & $\%$ & $n$ & $\%$ & 48,31 \\
& 29 & 39,19 & 14 & 93,33 & 43 & 0,000 \\
Atuação direta proponente & 41 & 55,41 & 13 & 86,67 & 54 & 60,67 & 0,024 \\
Capacitação e Assessoria técnica & 28 & 37,84 & 4 & 26,67 & 32 & 35,96 & 0,411 \\
Fortalecimento instit. locais & 28 & 37,84 & 5 & 33,33 & 33 & 37,08 & 0,742 \\
Mercado e cadeias produtivas & 5 & 6,76 & 4 & 26,67 & 9 & 10,11 & 0,020 \\
Pagamento a atores locais & & & & & & &
\end{tabular}

Fonte: Resultados da pesquisa.

estão mais atreladas ao papel do Estado. Na mesma linha, os PMC também se utilizam mais de Capacitação e assessoria técnica (86\%, contra 55\% dentre os PFP), uma forma de incentivo não monetário geralmente proposta como parte da visão abrangente de PSA (MURADIAN et al., 2010).

Além disso, mesmo adotando pagamentos monetários de forma mais frequente que os PFP, ainda assim a proporção de PMC que se utiliza desta ação é relativamente pequena em relação às demais ações adotadas. Para o REDD+, este fato pode de certa forma contrapor preocupações como a apresentada por Gómez-Baggethun et al. (2010), de que comunidades tradicionais possam abandonar suas motivações intrínsecas adotando comportamentos individualistas e mercantilistas frente à oferta de incentivos financeiros para a adoção de usos sustentáveis da terra. Entretanto, teoricamente, ainda permanece o risco de que, em vez das comunidades, os proponentes, atuando como intermediários e receptores iniciais dos pagamentos pelas transações de mercado, adotem tal perspectiva mercantilista, priorizando resultados de carbono em detrimento da biodiversidade e da qualidade de vida das populações locais.

Ainda assim, de forma geral, percebe-se que os PMC e PFP atuam de forma diversificada em relação às ações para implantação destas Atividades, tanto conduzindo as estratégias diretamente quanto atuando como intermediários para que outros atores possam, por sua vez, promover as estratégias. De maneira equivalente à análise feita sobre os Elementos, a avaliação das Atividades indica que os PMC não atuam exclusivamente dentro da lógica coaseana. Afinal, apesar de receberem os recursos por meio de transações de mercado, os proponentes destes projetos, na qualidade de intermediários, muitas vezes usam também outros mecanismos não baseados em pagamentos monetários para incentivar os usuários finais dos recursos a atingir os resultados esperados.

Com isto, curiosamente, estes projetos adotam práticas atreladas à visão abrangente de PSA (MURADIAN et al., 2010; SKUTSCH et al., 2011), isto é, adotando critérios de incentivo com base em esforços e concedendo incentivos não monetários, por exemplo, na forma de fortalecimento de instituições e de capacitação e assessoria. Esta situação está em linha com o argumento de Cacho, Lipper e Moss (2013) de que a atuação via instituições já existentes como ONGs, associações e governo é essencial para a viabilidade de projetos de mercado. Porém, também reforça a crítica à visão neoclássica de PSA, corroborando a posição de Skutsch et al. (2011), que afirmam:

"Although carbon payments are frequently posited as simple market transactions, they are likely to involve complex systems with multiple actors who interact in complicated ways".

Por fim, corrobora a visão de Fosci (2013a) para quem apenas o pagamento monetário não será suficiente para atingir os resultados esperados pelos neoclássicos em termos de eficiência. Para manter controlados os custos de transação e os custos de oportunidade é necessária a adoção de políticas e instituições que permitam superar barreiras legais, culturais, de conhecimento e de infraestrutura à adoção de alternativas sustentáveis de usos da terra.

A partir das características dos projetos apresentadas no estudo, nota-se que a concepção da economia ecológica parece estar mais aderente à realidade do REDD+ no contexto nacional, tanto pela defesa da participação do Estado e da necessidade de políticas 
públicas para a viabilização de mecanismos de incentivo, quanto pelo entendimento mais abrangente do conceito de PSA. Este entendimento parece capturar melhor as complexidades existentes no contexto dos projetos de REDD+, já que considera que esquemas de PSA podem ir além de transações de mercado e incluir outras formas de viabilizar os incentivos, tais como subsídios diretos e indiretos, implantação de políticas públicas e de incentivos não monetários, incluindo infraestrutura, capacitação e oferta de bens públicos.

\section{Conclusões}

Considerando-se as características identificadas para os 89 projetos analisados, é possível perceber claramente as adequações dos projetos sob cada modalidade de financiamento às diferentes concepções teóricas sobre instrumentos econômicos baseados em incentivo. São identificadas amplas diferenças entre o perfil dos projetos, relativas a prazos, participantes, abrangência, critérios de concessão de incentivos e práticas de MRV. O FA está fortemente alinhado aos conceitos propostos pela economia ecológica, contribuindo para que os PFP tenham características consideradas importantes para esta linha teórica. Os mercados voluntários, por sua vez, atuam principalmente com base na teoria coaseana, de forma que as características dos PMC são mais aderentes às premissas da economia ambiental neoclássica.

Contudo, em termos das atividades efetivamente implantadas esta diferenciação não é tão clara. Percebe-se que, in loco, ambas as modalidades recorrem tanto aos pagamentos monetários quanto aos incentivos não monetários, tais como o fortalecimento institucional, o provimento de infraestrutura etc. Assim, fica claro que, em aspectos centrais, a perspectiva puramente coaseana não dá conta da realidade de atuação prática dos projetos, os quais se mostram envolvidos em complexidades e exigências que podem minar algumas das bases teóricas usadas para justificar a característica custo efetiva do uso de mercados.

Nessa mesma linha, ao longo das negociações internacionais e da implantação dos projetos piloto, a proposta de basear o REDD+ puramente em um conceito coaseano no nível dos projetos parece ter sido revista em favor de uma abordagem mais abrangente e equilibrada entre pagamentos por resultados e implan- tação de políticas e instituições, de forma coerente com as complexidades que envolvem o tema florestal, tais como dispersão geográfica, as dificuldades de monitoramento e a multiplicidade de atores e interesses envolvidos. Esta situação pôde ser observada nos projetos piloto analisados, tanto sob a modalidade de mercado quanto de fundos públicos.

Por outro lado, de acordo com os defensores de esquemas de PSA coaseanos, este mecanismo deve ser usado de forma cuidadosa e seletiva, apenas onde as condições de direitos de propriedade, custo de oportunidade, custo de implantação dos usos sustentáveis da terra e custo de transação permitam um resultado efetivo e eficiente. Nas situações em que estes pré-requisitos não existam, o incentivo deveria vir de outras políticas públicas complementares, tais como comando e controle, ou de outros instrumentos econômicos e mecanismos de incentivo.

Ainda em favor da abordagem coaseana, pode-se esperar que ao longo dos próximos anos sejam desenvolvidas melhorias nas técnicas e tecnologias envolvidas com as práticas de MRV, principalmente em termos de sensoriamento remoto, reduzindo, assim, drasticamente os custos de transação envolvidos com projetos baseados em resultados. Estas tecnologias poderão ser usadas tanto para o melhor monitoramento de resultados ambientais quanto para facilitar o monitoramento social em busca de uma atuação socialmente justa e responsável.

Neste contexto, é defensável a adoção de modalidades mistas de financiamento que busquem financiar Elementos e Atividades de forma sinérgica e integrada, tanto nas fases preparatórias (readiness) quanto na fase de adoção em escala do REDD+. Afinal, além dos custos de oportunidade e de alteração das práticas de usos da terra, os custos para a manutenção das instituições e enforcement das políticas públicas, bem como para sua atualização e evolução, continuarão a existir ao longo do tempo.

A abordagem que vem se consolidando na UNFCCC, com uso de um mecanismo de incentivo baseado em resultados nacionais consolidados, seria compatível com modalidades mistas de financiamento, já que unifica sob um mesmo programa as perspectivas de implantação de políticas e instituições e de alterações nos usos da terra. Também permite a adoção de diversas estratégias locais para o incentivo a estes usos da terra, que podem ir desde pagamentos monetários 
mais próximos ao conceito coaseano até outros tipos de incentivos, como fortalecimento de instituições locais, capacitação, criação de infraestrutura e de melhores condições de mercado para produtos oriundos de manejo sustentável dos recursos naturais.

Em diversos países podem ser necessários longos processos para a elaboração e implantação de políticas e de estruturas mínimas para a viabilização deste tipo de mecanismo, passo que deve ser dado antes de se investir em mecanismos de mercado ou quaisquer outros mecanismos baseados em resultados. No Brasil, contudo, já há condições muito mais favoráveis para que isto ocorra, como foi possível observar pelos esforços de monitoramento e enforcement de políticas, bem como pelos resultados atingidos ao longo da última década.

Desta forma, faz sentido que na realidade brasileira sejam financiadas simultaneamente ações relacionadas a Elementos e Atividades. O Fundo Amazônia, principal iniciativa atual do governo brasileiro para o incentivo ao REDD+, busca fazer este papel. No entanto, os projetos financiados pelo mercado também se mostraram capazes de contribuir para esta abordagem, apropriada como forma de aproximar ações de usos da terra e de política, e deveriam ser igualmente considerados como parte da implantação do REDD+ no Brasil.

\section{Referências}

AGRAWAL, A., NEPSTAD, D. e CHHATRE, A. Reducing emissions from deforestation and forest degradation. Annual Review of Environment and Resources, v. 36, n. 1, p. 373-396, 2011.

ANDRADE, D. C. e FASIABEN, M. DO C. R. A utilização dos instrumentos de política ambiental para a preservação do meio ambiente: o caso dos Pagamentos por Serviços Ecossistêmicos (PSE). Revista Economia Ensaios, v. 24, n. 1, 2010.

ANDRADE, D. C. e SIMÕES, M. Limitações da abordagem coaseana à definição do instrumento de Pagamento por Serviços Ambientais (PSA). Sustentabilidade em Debate, v. 4, n. 1, p. 59-78, 2013.

ANGELSEN, A. e MCNEILL, D. The evolution of REDD+. In: Analysing REDD+ challenges and choices. Bogor, Indonesia: Center for International Forestry Research (CIFOR), 2012.
ANGELSEN, A. e WERTZ-KANOUNNIKOFF, S. What are the key design issues for REDD and the criteria for assessing options? In: Moving ahead with REDD: issues, options and implications. Bogor, Indonesia: Center for International Forestry Research (CIFOR), 2008.

ARIMA, E. Y. et al. Public policies can reduce tropical deforestation: Lessons and challenges from Brazil. Land Use Policy, v. 41, p. 465-473, nov. 2014.

ARRAES, R. A. E., MARIANO, F. Z. e SIMONASSI, A. G. Causas do desmatamento no Brasil e seu ordenamento no contexto mundial. Revista de Economia e Sociologia Rural, v. 50, n. 1, p. 119-140, mar. 2012.

BNDES. Relatório de Atividades 2013 - Fundo Amazônia. Bando Nacional do Desenvolvimento, jun. 2014. Disponível em: < http://www.fundoamazonia.gov.br/ FundoAmazonia/export/sites/default/site_pt/Galerias/ Arquivos/Relatorio_Anual/RAFA_virtual_PORT_2013. pdf>. Acesso em: 22 mar. 2015.

BÖRNER, J. et al. Direct conservation payments in the Brazilian Amazon: scope and equity implications. Ecological Economics, v. 69, n. 6, p. 1272-1282, 1 abr. 2010.

CACHO, O. J., LIPPER, L. e MOSS, J. Transaction costs of carbon offset projects: a comparative study. Ecological Economics, v. 88, p. 232-243, abr. 2013.

CÁNEPA, E. Economia da poluição. In: MAY, P. H., LUSTOSA, M. C. e VINHA, V. Economia do meio ambiente: teoria e prática. Rio de Janeiro: Elsevier Campus, 2003.

COASE, R. H. The problem of social cost. Journal of Law and Economics, v. 56, n. 4, p. 837-877, 1960.

COMMON, M. S. e STAGL, S. Ecological economics: an introduction. Cambridge, UK: Cambridge University Press, 2005.

CONOVER, W. J. Practical nonparametric statistics. 3. ed. New York: Wiley, 1999.

CORBERA, E. Problematizing REDD+ as an experiment in payments for ecosystem services. Current Opinion in Environmental Sustainability, v. 4, n. 6, p. 612-619, dez. 2012.

DALY, H. E. Ecological economics and the ecology of economics: essays in criticism. Cheltenham, UK; Northampton, MA, USA: E. Elgar, 1999.

DALY, H. E. e FARLEY, J. C. Ecological economics: principles and applications. Washington: Island Press, 2004.

DUCHELLE, A. E. et al. Linking forest tenure reform, environmental compliance, and incentives: Lessons from REDD+ Initiatives in the Brazilian Amazon. World Development, v. 55, p. 53-67, mar. 2014. 
ENGEL, S., PAGIOLA, S. e WUNDER, S. Designing payments for environmental services in theory and practice: an overview of the issues. Ecological Economics, v. 65, n. 4 , p. 663-674, 1 mai. 2008.

FERREIRA, M. D. P. e COELHO, A. B. Desmatamento recente nos estados da Amazônia Legal: uma análise da contribuição dos preços agrícolas e das políticas governamentais. Revista de Economia e Sociologia Rural, v. 53, n. 1, p. 91-108, mar. 2015.

FIGUEROA, R. e MILLS, C. Justiça ambiental. In: JAMIESON, D. (Ed.). Manual de Filosofia do Ambiente. Lisboa: Piaget, 2003. p. 437-469.

FOSCI, M. The economic case for prioritizing governance over financial incentives in REDD+. Climate Policy, v. 13, n. 2, p. 170-190, mar. 2013a.

Balance sheet in the REDD+: are global estimates measuring the wrong costs? Ecological Economics, v. 89, p. 196-200, maio 2013b.

FRANKFORT-NACHMIAS, C. e NACHMIAS, D. Research methods in the social sciences. New York: Worth Publishers, 2008.

GOLDSTEIN, A. e GONZALEZ, G. Turning over a New Leaf: State of the Forest Carbon Markets 2014. Washington, DC: Forest Trends Ecosystem Marketplace, 2014. Disponível em: <http://www.forest-trends.org/ documents/files/doc_4770.pdf $>$. Acesso em: 22 mar. 2015.

GÓMEZ-BAGGETHUN, E. et al. The history of ecosystem services in economic theory and practice: From early notions to markets and payment schemes. Ecological Economics, v. 69, n. 6, p. 1209-1218, 1 abr. 2010.

GUEDES, F. B.; SEEHUSEN, S. E. (Eds.). Pagamentos por serviços ambientais na Mata Atlântica: lições aprendidas e desafios. Brasília: Ministério do Meio Ambiente, 2011.

HALL, A. Combating deforestation through REDD+ in the Brazilian Amazon: a New Social Contract? Sustentabilidade em Debate, v. 4, n. 1, p. 79-98, 2013.

HAMRICK, K. Ahead of the curve: state of the Voluntary Carbon Markets 2015. Washington, DC: Forest Trends Ecosystem Marketplace, 2015. Disponível em: < http:// forest-trends.org/releases/uploads/SOVCM2015 FullReport.pdf >. Acesso em: 14 dez. 2015.

INPE. Prodes - Taxas Anuais 1988-2016. Disponível em: $<$ http://www.obt.inpe.br/prodes/prodes_1988_2016n. htm > . Acesso em: 21 abr. 2017.

IPCC. Chapter 11 - Agriculture, Forestry and Other Land Use (AFOLU). In: Climate Change 2014, Mitigation of Climate Change. Contribution of Working Group III to the Fifth Assessment Report of the Intergovernmental Panel on Climate Change. Cambridge: Cambridge University Press, 2014.

JACK, B. K., KOUSKY, C. e SIMS, K. R. Designing payments for ecosystem services: lessons from previous experience with incentive-based mechanisms. Proceedings of the National Academy of Sciences, v. 105, n. 28, p. 9465-9470, 2008.

JACOBS, M. La economia verde: médio ambiente, desarrollo sostenible y la politica del futuro. Barcelona: Icaria, FUHEM, 1997.

LANDELL-MILLS, N. e PORRAS, I. T. Silver bullet or fools' gold?: a global review of markets for forest environmental services and their impact on the poor. London: International Institute for Environment and Development, 2002.

LAPOLA, D. M. et al. Pervasive transition of the Brazilian land-use system. Nature Climate Change, v. 4, n. 1, p. 27-35, 20 dez. 2013.

LEDERER, M. From CDM to REDD+ - What do we know for setting up effective and legitimate carbon governance? Ecological Economics, v. 70, n. 11, p. 19001907, 2011.

LEVIN, J. e FOX, J. A. Estatística para ciências humanas. São Paulo: Pearson: Prentice Hall, 2004.

LUSTOSA, M. C. J., CÁNEPA, E. M. e YOUNG, C. E. F. Política ambiental. In: MAY, P. H., LUSTOSA, M. C. e VINHA, V. Economia do meio ambiente: teoria e prática. Rio de Janeiro: Elsevier, 2003.

MAHANTY, S., SUICH, H. e TACCONI, L. Access and benefits in payments for environmental services and implications for REDD+: Lessons from seven PES schemes. Land Use Policy, v. 31, p. 38-47, mar. 2013.

MARCOVITCH, J. e PINSKY, V. C. Amazon Fund: financing deforestation avoidance. Revista de Administração, São Paulo, v. 49, n. 2, p. 280-290, jun. 2014.

MARTINEZ-ALIER, J. e ROCA JUSMET, J. Economía ecológica y política ambiental. 2. ed. corr. y aum ed. México: Fondo de Cultura Económica, 2001.

MAY, P.H. Mecanismos de mercado para uma economia verde. In: Política Ambiental n. 8. Belo Horizonte: Conservação Internacional, 2011.

MCDERMOTT, C. L., IRLAND, L. C. e PACHECO, P. Forest certification and legality initiatives in the Brazilian Amazon: lessons for effective and equitable forest governance. Forest Policy and Economics, v. 50, p. 134-142, jan. 2015. 
MILLENNIUM ECOSYSTEM ASSESSMENT. Ecosystems and human well-being: synthesis. Washington, DC: Island Press, 2005.

MINANG, P. A. e VAN NOORDWIJK, M. Design challenges for achieving reduced emissions from deforestation and forest degradation through conservation: Leveraging multiple paradigms at the tropical forest margins. Land Use Policy, v. 31, p. 61-70, 2013.

MOTTA, R. S. D. Economia ambiental. Rio de Janeiro: FGV Editora, 2006.

- Valoração e precificação dos recursos ambientais para uma economia verde. In: Política Ambiental n. 8. Belo Horizonte: Conservação Internacional, 2011.

MURADIAN, R. et al. Reconciling theory and practice: An alternative conceptual framework for understanding payments for environmental services. Ecological Economics, v. 69, n. 6, p. 1202-1208, 1 abr. 2010.

MURADIAN, R. et al. Payments for ecosystem services and the fatal attraction of win-win solutions. Conservation Letters, v. 6, n. 4, p. 274-279, 2013.

NORGAARD, R. B. Ecosystem services: from eyeopening metaphor to complexity blinder. Ecological Economics. v. 69, n. 6, p. 1219-1227, 1 abr. 2010.

ROCKSTRÖM, J. et al. A safe operating space for humanity. Nature, v. 461, n. 7263, p. 472-475, 24 set. 2009.

SANTOS, R. F. e VIVAN, J. L. Pagamento por Serviços Ecossistêmicos em perspectiva comparada: recomendações para tomada de decisão. Brasília: Projeto Apoio aos Diálogos Setoriais UE-Brasil, 2012.

SILVA-CHÁVEZ, G., SCHAAP, B. e BREITFELLER, J. REDD+ Finance Flows 2009-2014: Trends and Lessons Learned in REDDX Countries. Washington, DC: Forest Trends, nov. 2015. Disponível em: < http://www.foresttrends.org/documents/files/doc_5029.pdf>. Acesso em: 14 dez. 2015.

SIMÃO, N., MARTINS, G. e FAVARETO, A. As teorias econômicas implícitas no Protocolo de Kyoto. Sustentabilidade em Debate, v. 5, n. 2, p. 179-202, 9 set. 2014.

SKUTSCH, M. et al. Alternative models for carbon payments to communities under REDD+: A comparison using the Polis model of actor inducements. Environmental Science E Policy, 2011.

SOARES-FILHO, B. et al. Cracking Brazil's Forest Code. Science, v. 344, n. 6182, p. 363-364, 25 abr. 2014.

STEFFEN, W. et al. Planetary boundaries: guiding human development on a changing planet. Science, v. 347 , n. 6223 , p. 736,13 fev. 2015.

STRECK, C. Financing REDD+: matching needs and ends. Current Opinion in Environmental Sustainability, 4/6 Climate systems, v. 4, n. 6, p. 628-637, dez. 2012.

THOMPSON, M. C., BARUAH, M. e CARR, E. R. Seeing REDD+ as a project of environmental governance. Environmental Science E Policy, v. 14, n. 2, p. 100-110, 2011.

UNFCCC. Kyoto Protocol to the United Nations Framework Convention on Climate Change. Geneva: UNFCCC, 1998.

Report of the Conference of the Parties on its sixteenth session, held in Cancun from 29 november to 10 december 2010. Geneva: UNFCCC, 2011.

. Report of the Conference of the Parties on its seventeenth session, held in Durban from 28 november to 11 december 2011. Geneva: UNFCCC, 2012.

. Report of the Conference of the Parties on its Twentyfirst session, held in Paris from 30 november to 11 december 2015. Geneva: UNFCCC, 2016.

. Report of the Conference of the Parties on its twentysecond session, held in Marrakech from 7 to 18 november 2016. Geneva: UNFCCC, 2017.

VIANA, V. M. Financing REDD: how government funds can work with the carbon market. International Institute for Environment and Development Policy Brief, 2009.

WUNDER, S. The efficiency of payments for environmental services in tropical conservation. Conservation Biology, v. 21, n. 1, p. 48-58, 1 fev. 2007.

WUNDER, S. REDD: de boas idéias a realidades complicadas. Boletim da Sociedade Brasileira de Economia Ecológica, n. 23/24, 2010.

. When payments for environmental services will work for conservation. Conservation Letters, v. 6, n. 4 , p. $230-237,1$ jul. 2013. 